\title{
Approaching glioblastoma during COVID-19 pandemic: current recommendations and considerations in Brazil
}

\author{
Abordando glioblastomas durante a pandemia pelo COVID-19: recomendações atuais \\ e considerações no Brasil \\ Gabriel Novaes de Rezende BATISTELLA', Adrialdo José SANTOS', Manoel Antonio de PAIVA NETO', \\ Robson FERRIGNO², Veridiana Pires de CAMARGO³, João Norberto STAVALE', \\ Marcos Vinicius Calfat MALDAUN ${ }^{4}$
}

\begin{abstract}
Background: Cancer patients in general and glioblastoma patients, in particular, have an increased risk of developing complications from the severe acute respiratory syndrome coronavirus 2 (SARS-CoV-2), and reaching a balance between the risk of exposure to infection and the clinical benefit of their treatment is ideal. The aggressive behavior of this group of tumors justifies the need for a multidisciplinary team to assist in clinical decisions during the current pandemic. Brazil is now ranked \#2 in the number of cases and deaths from COVID-19 pandemic, and existing disparities in the treatment of neuro-oncology patients in Brazil will challenge the clinical and surgical decisions of this population, possibly affecting global survival. Objective: To search the literature about the management of glioblastomas during COVID-19 pandemic to guide surgical and clinical decisions in this population of patients in Brazil. Methods: We performed a systematic search on the PubMed electronic database targeting consensus statements concerning glioblastoma approaches during COVID-19 pandemic up to July 18, 2020. Results: When approaching glioblastoma during the COVID-19 pandemic, important parameters that help in the decision-making process are age, performance status, tumor molecular profile, and patient consent. Younger patients should follow the standard protocol after maximal safe resection, mainly those with MGMT methylated tumors. Aged and underperforming patients should be carefully evaluated, and probably a monotherapy scheme is to be considered. Centers are advised to engage in telemedicine and to elaborate means to reduce local infection. Conclusion: Approaching glioblastoma during the COVID-19 pandemic will be challenging worldwide, but particularly in Brazil, where a significant inequality of healthcare exists.
\end{abstract}

Keywords: Coronavirus Infections; Neuro-Oncology; High-Grade Glioma; Glioblastoma.

\section{RESUMO}

Introdução: Pacientes com câncer, em geral, e particularmente pacientes com glioblastoma estão sob elevado risco de desenvolver síndrome respiratória aguda grave devido à infecção pelo SARS-CoV-2, e alcançar um equilíbrio entre risco de exposição à infecção e benefício clínico do tratamento seria o ideal. O comportamento agressivo desse grupo de tumores justifica a necessidade de equipe multidisciplinar para auxiliar nas decisões clínicas durante a pandemia vigente. O Brasil ocupa hoje o segundo lugar em número de casos e óbitos pela COVID-19, e as atuais disparidades no tratamento de pacientes neuro-oncológicos desafiarão as decisões clínicas e cirúrgicas dessa população, possivelmente afetando a sobrevida global. Objetivo: Guiar decisões clínicas e cirúrgicas relacionadas ao manejo de glioblastoma durante a pandemia pelo COVID-19 no Brasil por meio de pesquisa em literatura. Métodos: Busca sistemática no banco de dados eletrônico da PubMed por estudos ou consensos quanto à abordagem de glioblastoma durante a pandemia por

\footnotetext{
${ }^{1}$ Universidade Federal de São Paulo, Escola Paulista de Medicina, Departamento de Neurologia e Neurocirurgia, São Paulo SP, Brazil.

${ }^{2}$ Hospital Beneficência Portuguesa de São Paulo, Departamento de Oncologia de Radiação, São Paulo SP, Brazil.

${ }^{3}$ Oncologia D’Or, São Paulo SP, Brazil.

${ }^{4}$ Hospital Sírio-Libanês, Departamento de Neurocirurgia, São Paulo SP, Brazil.
}

Gabriel Novaes de Rezende BATISTELLA (iD https://orcid.org/0000-0002-8686-3354; Adrialdo José SANTOS (DD https://orcid.org/0000-0003-4513-6262; Manoel Antonio de PAIVA NETO (D) https://orcid.org/0000-0002-1144-7487; Robson FERRIGNO iD https://orcid.org/0000-0002-0735-240X; Veridiana Pires de CAMARGO (D) https://orcid.org/0000-0001-8067-386X; João Norberto STAVALE (iD) https://orcid.org/0000-0002-9141-0106; Marcos Vinicius Calfat MALDAUN (iD https://orcid.org/0000-0003-0463-2235

Correspondence: Gabriel Novaes de Rezende Batistella; E-mail: batistella@unifesp.br

Conflict of interest: There is no conflict of interest to declare.

Authors' contributions: GNRB: led the conceptualization and methodology, managed the project, and was responsible for writing the original draft, as well as reviewing and editing it; AJS: participated in the methodology, supervision, and writing/review and editing; MAPN: participated in the supervision, visualization, writing of the original draft, and reviewing and editing; RF: participated in the conceptualization, methodology, supervision, writing of the original draft, and reviewing and editing; VPC: participated in the conceptualization and methodology; JNS: participated in the conceptualization, formal analysis, methodology, project management, supervision, writing of the original draft, and reviewing and editing; MVCM: participated in the formal analysis, methodology, supervision, reviewing, and editing of the original draft.

Received on September 10, 2020; Received in its final form on October 18, 2020; Accepted on October $28,2020$. 
COVID-19 até 18/07/2020. Resultado: Ao abordar o glioblastoma durante a pandemia pela COVID-19, parâmetros importantes que auxiliam no processo de tomada de decisão são idade, desempenho, perfil molecular tumoral e consentimento do paciente. Pacientes jovens devem seguir protocolo padrão após máxima ressecção cirúrgica, principalmente aqueles com metilação do promotor MGMT. Idosos e pacientes debilitados devem ser cuidadosamente avaliados, e monoterapia deve ser provavelmente considerada. Centros de saúde são orientados a utilizar-se da telemedicina e de meios para reduzir infecção local. Conclusão: A abordagem do glioblastoma durante a pandemia por COVID-19 será mundialmente desafiadora, mas particularmente no Brasil, onde ainda existe significativa inequidade no cuidado com a saúde.

Palavras-chave: Infecções por Coronavírus; Neuro-Oncologia; Glioma de Alto Grau; Glioblastoma.

\section{INTRODUCTION}

The ongoing severe acute respiratory syndrome coronavirus 2 (SARS-Cov-2) has wholly changed healthcare worldwide, including the care of neuro-oncology patients with high-grade gliomas. In this review, current recommendations for the treatment of high-grade gliomas during the pandemic are presented to guide clinical practice. COVID-19 pandemic will require individual centers to shift their focus and resources to allocate patients and provide a safe environment. It will also demand physicians to employ clinical care in different manners and to an interdisciplinary extent.

Current publications provide mostly a framework of evidence-based care to prolong overall survival and progressionfree survival. Each health service should manage resources to avoid the potential for undertreatment of cancer. During the current pandemic, neuro-oncology treatment decisions will challenge clinicians, surgeons, and hospitals, and the best efforts to deliver treatment should prevail.

High-grade gliomas comprise a heterogeneous group of aggressive and incurable tumors, usually requiring maximal safe surgical resection, radiotherapy, and chemotherapy as an upfront treatment to reach the best overall survival and progression-free survival. COVID-19 pandemic broke the traditional workflow employed during neuro-oncology therapy in many centers. Glioblastoma patients are usually offered the standard treatment protocol established since 2005 (Stupp protocol). Still, aged patients or patients with poor performance status may benefit from hypofractionated protocols or even monotherapy with radiotherapy or temozolomide. Molecular changes like O-6-methylguanineDNA methyltransferase (MGMT) promoter methylation and Isocitrate dehydrogenase (IDH) mutation should be used to stratify best treatment among older patients.

Here, a group of Brazilian neuro-oncology experts gathered together to suggest treatment approaches during the COVID-19 pandemic in Brazil.

\section{GLIOBLASTOMA}

Glioblastoma is currently treated according to EORTCNCIC (Stupp protocol), where maximal safe resection is followed by concurrent chemo-radiotherapy (CRT) and six cycles of adjuvant chemotherapy with temozolomide ${ }^{1}$
(Figure 1). Patients with MGMT promoter methylation status reached better overall survival than unmethylated ones, with about $50 \%$ longer median survival for those treated with temozolomide ${ }^{2,3}$. Aged patients generally have a worse prognosis and are less tolerant to toxicities. Still, a recent study demonstrated that hypofractionated radiotherapy (40Gy/15 fractions of $2.67 \mathrm{~Gy}$ over three weeks) is as effective as the standard 60Gy over six weeks. The association of temozolomide showed better overall survival when compared to radiotherapy alone ${ }^{4}$. Treatment with either temozolomide or radiotherapy alone is an option, mainly for those with poor performance status, and it should be guided by MGMT promoter methylation whenever possible ${ }^{5}$.

\section{Neurosurgery}

Maximal safe resection is recommended for glioblastoma, and since it offers a benefit in overall survival (OS) and quality of life (QOL), it should be considered a priority ${ }^{6,7}$. Surgery also makes histological and molecular analysis possible, which might inform treatment decisions.

When admitting neuro-oncological patients, some safety issues should always be considered, such as active screening for flu symptoms, reverse transcription polymerase chain reaction (rt-PCR) for the COVID-19 test, and getting an epidemiological history focusing on COVID-19. The staff is guided to wear additional Personal Protective Equipment (PPE), such as N95 and face shields ${ }^{8}$. Some centers also recommend acquiring a pulmonary computed tomography (CT) for preliminary diagnosis of COVID-19 before hospitalization $^{9,10}$. For patients whose tests came out negative, hospital admission should be through a particular lane to avoid cross-infection, and individual accommodation with rigorous quarantine should be applied. Infected patients should have surgery postponed until infection ceases. Patients with life-threatening conditions can bypass all these steps, they should be kept in individual accommodations after surgery, and later analysis would guide different paces. All postoperative patients should be regarded as suspected cases, and quarantine for at least two weeks is recommended ${ }^{9}$.

Awake craniotomy is a crucial procedure to achieve maximum safe resection in some patients with high-grade gliomas, but this technique can be considered high-risk in COVID-19 pandemic times. Patients require very close and direct contact between the neurophysiologist during stimulation and a lot of technical personnel. Patients infected with 

receive hypofractionated schedules instead of a six-week traditional radiotherapy course. Data supporting this recommendation come from earlier trials concerning older patients, and non-inferiority results reinforce some of the current suggestions ${ }^{12}$. Roa et al. reported results of a prospective study which randomized 100 patients with GBM and aged 60 years old or older to receive standard RT fractionation (60 Gy in 30 fractions) or a hypofractionated regimen (40 Gy in 15 fractions). They found no difference in survival between patients receiving standard RT or short-course $\mathrm{RT}^{14}$. The International Atomic Energy Agency (IAEA) conducted an international prospective and randomized trial to compare two RT regimens (40 Gy in 15 fractions and 25 Gy in 5 fractions) on the outcome of 98 patients with GBM and aged 50 years old or older. They found no differences in OS time, progression-free survival time, and QOL between patients receiving the two RT regimens. The authors concluded that a short 1-week RT regimen might be recommended as a treatment option for aged or frail patients with newly diagnosed $\mathrm{GBM}^{15}$. Perry et al., through a prospective and randomized study involving 562 patients with GBM and aged 65 years old or older, showed median OS benefit when combining CT with temozolomide (TMZ) to hypofractionated RT with 40 Gy in 15 fractions ( 9.3 vs. 7.6 months; $\mathrm{p}<0.001)^{4}$.

For patients younger than 60-65 years of age and with good performance status and MGMT methylated tumors, maintaining standard treatment with 60Gy in 30 fractions according to Stupp Protocol is reasonable. However, patients should be offered the possibility of reducing the number of visits, mainly because they are dealing with an incurable type of cancer ${ }^{12}$.

\section{Chemotherapy}

The leading cause of mortality from SARS-CoV-2 is the acute respiratory distress syndrome (ARDS) and many events surrounding a hyperinflammatory syndrome leading to multiorgan failure ${ }^{16}$. In a retrospective, multicenter cohort study in Wuhan, the presence of lymphopenia in hospitalized patients with COVID-19 was a risk factor for death and usually seen in severe cases ${ }^{17}$. Currently, temozolomide is the main chemotherapy used to treat glioblastoma patients, employed in the concurrent and adjuvant phase, and can even be given after disease recurrence ${ }^{1,2,3}$. Temozolomide added in the upfront treatment of glioblastoma resulted in OS benefit, mainly for those harboring an MGMT promoter methylation status ${ }^{3}$, but also determined about $14 \%$ of grade 3 or 4 hematologic toxicities in the studied cohort of patients ${ }^{1}$. Therefore, the decision to keep or withhold chemotherapy should be carefully studied after many considerations, like the presence of a good molecular profile, the local situation despite COVID-19 pandemic, patients' decision and patient adherence to treatment and risk of hematologic toxicities.

The National Comprehensive Cancer Network (NCCN) guidelines claim that temozolomide's omission during glioblastoma treatment is possible, mainly for those MGMT unmethylated patients and the elderly with comorbidities, but could also be reasonable during this pandemic ${ }^{18}$. In Brazil, temozolomide is still not widely available in most states $^{19}$, and patients with health insurance are those with the possibility of acquiring treatment. Access to MGMT promoter status is also not widely available for most patients, which could harden clinical decisions.

It is reasonable to prioritize temozolomide for patients with MGMT methylated status ${ }^{3}$ and IDH mutated tumors ${ }^{20}$, while keeping close attention to treatment toxicities and scheduling regular blood exams. High-grade gliomas that harbor a mutation in IDH might benefit from the addition of temozolomide to the treatment protocol; the EORTC phase III CATNON trial demonstrated that IDH mutation was predictive of a significant benefit from adjuvant temozolomide, with even the benefit of using it in concurrency ${ }^{20,21}$.

The CeTeG/NOA-09 trial recently investigated the effect of lomustine (CCNU) with temozolomide vs. the standard regimen for newly diagnosed MGMT methylated glioblastomas undergoing radiotherapy in a phase III trial ${ }^{22}$. This study suggested that this combination might improve OS compared to temozolomide alone in MGMT-methylated patients, but the toxicities when both agents were combined were significantly higher. The decision to employ this strategy during the COVID-19 pandemic should be critically reviewed, and is probably not recommended ${ }^{12}$.

\section{The use of corticosteroids}

Glioblastoma frequently presents with symptomatic peritumoral vasogenic edema, and dexamethasone alleviated neurological deficits and signs of increased intracranial pressure. Low doses administered once or twice daily are sufficient in most cases ${ }^{23}$. Many studies suggest that caution should be used when employing steroids in neuro-oncology due to a detrimental effect on survival outcomes. In an independent analysis of three patients' cohorts, Pitter et al. showed that the use of corticosteroids during radiotherapy is an independent indicator of shorter survival in glioblastoma patients. Probably dexamethasone-induced anti-proliferative effects can protect the tumor from radiation or chemotherapy-induced genotoxic stress ${ }^{24}$.

The RECOVERY (Randomised Evaluation of COVID-19 Therapy) trial recently announced that dexamethasone given once daily at the dose of $6 \mathrm{mg}$ once per day (either by mouth or intravenous injection) for ten days reduced deaths by one-third in ventilated patients and by one fifth in other patients receiving oxygen only ${ }^{25}$. Previous data suggested that patients with SARS-CoV-2 infection would not benefit from corticosteroid treatment, and its usage should be cautioned considered ${ }^{26}$.

Regardless of the current pandemic, the beneficial antiinflammatory and anti-edematous effects should be cautiously weighed against the potential adverse effects in 
glioblastoma treatment and the lowest dose capable of controlling symptoms should be chosen.

Approaching glioblastoma patients during the COVID-19 pandemic will be challenging in most centers that treat neuro-oncological patients. In Brazil, significant disparities in healthcare among states will confront physicians to make proper treatment decisions. Patients with good performance status and good molecular profile (mainly MGMT promoter methylation and IDH mutation) should receive the standard protocol of treatment with maximal safe resection followed by concurrent chemo-radiotherapy and adjuvant chemotherapy with temozolomide whenever possible. Older patients and those with poor performance status should be carefully treated, and probably a monotherapy regimen might best fit during the COVID-19 pandemic, in case patients with good performance status and no comorbidities could benefit from hypofractionated protocols with temozolomide (Figure 2). The current situation challenges us, and delivering the best healthcare and employing new ways to communicate with our patients is essential. All efforts should focus on safety and not compromise patient care and survival.

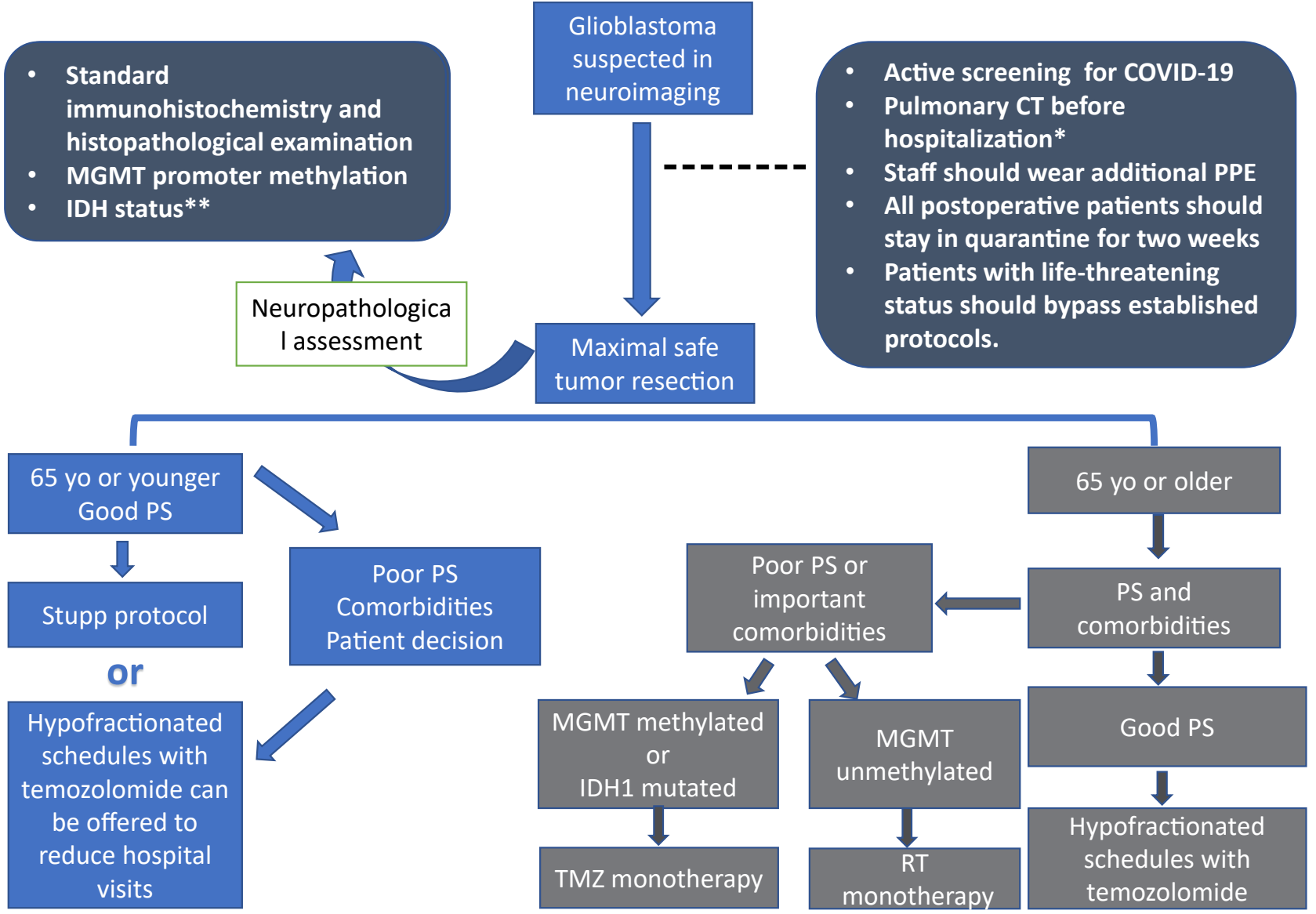

MGMT: $0^{6}$-Methylguanine-DNA methyltransferase; CT: computer tomography; yo: years-old; PS: performance status; IDH: isocitrate dehydrogenase; TMZ:

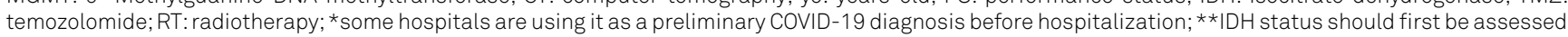
through immunohistochemistry assays.

Figure 2. Proposed flowchart for the treatment of patients with glioblastoma during COVID-19 pandemic.

\section{References}

1. Stupp R, Mason WP, van den Bent MJ, Weller M, Fisher B, Taphoorn MJB, et al. Radiotherapy plus concomitant and adjuvant temozolomide for glioblastoma. N Engl J Med. 2005 Mar;352(10):987-96. https://doi.org/10.1056/NEJMoa043330

2. Wen PY, Weller M, Lee EQ, Alexander BM, Barnholtz-Sloan JS, Barthel FP, et al. Glioblastoma in adults: a Society for NeuroOncology (SNO) and European Society of Neuro-Oncology (EANO) consensus review on current management and future directions.
Neuro Oncol. 2020 Aug;22(8):1073-13. https://doi.org/10.1093/ neuonc/noaa106

3. Stupp R, Hegi ME, Mason WP, van den Bent MJ, Taphoorn MJB, Janzer RC, et al. Effects of radiotherapy with concomitant and adjuvant temozolomide versus radiotherapy alone on survival in glioblastoma in a randomised phase III study: 5-year analysis of the EORTC-NCIC trial. Lancet Oncol. 2009 May;10(5):459-66. https://doi. org/10.1016/S1470-2045(09)70025-7 
4. Perry JR, Laperriere N, O'Callaghan CJ, Brandes AA, Menten J, Phillips $\mathrm{C}$, et al. Short-course radiation plus temozolomide in elderly patients with glioblastoma. N Engl J Med. 2017 Mar;376(11):1027-37. https://doi.org/10.1056/NEJMoa1611977

5. National Comprehensive Cancer Network. Central Nervous System Cancers. 2020. Available from: https://www.nccn.org/store/login/ login.aspx?ReturnURL=https://www.nccn.org/professionals/ physician_gls/pdf/cns.pdf

6. Bloch O, Han SJ, Cha S, Sun MZ, Aghi MK, McDermott MW, et al. Impact of extent of resection for recurrent glioblastoma on overall survival: clinical article.J Neurosurg. 2012 Dec;117(6):1032-8. https://doi.org/10.3171/2012.9.JNS12504

7. Sanai N, Polley MY, McDermott MW, Parsa AT, Berger MS. An extent of resection threshold for newly diagnosed glioblastomas. J Neurosurg. 2011 Jul;115(1):3-8. https://doi.org/10.3171/2011.2.jns10998

8. Cenzato M, Dimeco F, Fontanella M, Locatelli D, Servadei F. Editorial. Neurosurgery in the storm of COVID-19: suggestions from the Lombardy region, Italy (ex malo bonum). J Neurosurg. 2020 Apr;1-2. https://doi.org/10.3171/2020.3.JNS20960

9. Tan YT, Wang JW, Zhao K, Han L, Zhang HQ, Niu HQ, et al. Preliminary recommendations for surgical practice of Neurosurgery Department in the central epidemic area of 2019 coronavirus infection. Curr Med Sci. 2020 Apr;40(2):281-4. https://doi. org/10.1007/s11596-020-2173-5

10. Hu YJ, Zhang JM, Chen ZP. Experiences of practicing surgical neuro-oncology during the COVID-19 pandemic. J Neurooncol. 2020 Apr;148(1):199-200. https://doi.org/10.1007/s11060-020-03489-6

11. Núñez-Velasco S, Mercado-Pimentel R, Rodríguez-Arias R. Letter to the editor: awake craniotomy for intracranial gliomas during COVID-19 pandemic. World Neurosurg. 2020 Aug;140:470-2. https:// doi.org/10.1016/j.wneu.2020.05.219

12. Bernhardt D, Wick W, Weiss SE, Sahgal A, Lo SS, Suh JH, et al. Neurooncology management during the COVID-19 pandemic with a focus on WHO grade III and IV gliomas. Neuro Oncol. 2020 May;22(7):92835. https://doi.org/10.1093/neuonc/noaa113

13. Kooraki S, Hosseiny M, Myers L, Gholamrezanezhad A. Coronavirus (COVID-19) outbreak: what the department of radiology should know. J Am Coll Radiol. 2020 Apr;17(4):447-51. https://doi.org/10.1016/j. jacr.2020.02.008

14. Roa, W. et al. Abbreviated course of radiation therapy in older patients with glioblastoma multiforme: a prospective randomized clinical trial.J Clin Oncol. 2004 May;22(9):1583-8. https://doi. org/10.1200/JCO.2004.06.082

15. Roa W, Kepka L, Kumar N, Sinaika V, Matiello J, Lomidze D, et al. International Atomic Energy Agency randomized phase iii study of radiation therapy in elderly and/or frail patients with newly diagnosed glioblastoma multiforme. J Clin Oncol. 2015 Dec;33(35):4145-50. https://doi.org/10.1200/JC0.2015.62.6606

16. Ruan $Q$, Yang K, Wang W, Jiang L, Song J. Clinical predictors of mortality due to COVID-19 based on an analysis of data of
150 patients from Wuhan, China. Intensive Care Med. 2020 May;46(5):846-8. https://doi.org/10.1007/s00134-020-05991-x

17. Zhou F, Yu T, Du R, Fan G, Liu Y, Liu Z, et al. Clinical course and risk factors for mortality of adult inpatients with COVID-19 in Wuhan, China: a retrospective cohort study. Lancet. 2020 Mar;395(10229):1054-62. https://doi.org/10.1016/S01406736(20)30566-3

18. Nabors LB, Portnow J, Ammirati M, Baehring J, Brem H, Butowski N, et al. NCCN Guidelines Insights: Central Nervous System Cancers, Version 1.2017.J Natl Compr Canc Netw. 2017 Nov;15(11):1331-45. https://doi.org/10.6004/jnccn.2017.0166

19. Vidal TJ, Moraes EL, Retto MPF, Silva M. The lawsuits to antineoplastic drugs: the tip of an iceberg? Ciênc Saúde Coletiva. 2017 Aug;22(8):2539-48. https://doi.org/10.1590/141381232017228.07982017

20. van den Bent MJ, Erridge S, Vogelbaum MA, Nowak AK, Sanson M, Brandes AA, et al. Second interim and first molecular analysis of the EORTC randomized phase III intergroup CATNON trial on concurrent and adjuvant temozolomide in anaplastic glioma without $1 \mathrm{p} / 19 \mathrm{q}$ codeletion. J Clin Oncol. 2019 May;37(15 Suppl):2000-2000. https:// doi.org/10.1200/JCO.2019.37.15_suppl.2000

21. van ben Bent MJ, Baumert B, Erridge SC, Vogelbaum MA, Nowak AK, Sanson M, et al. Interim results from the CATNON trial (EORTC study 26053-22054) of treatment with concurrent and adjuvant temozolomide for $1 \mathrm{p} / 19 \mathrm{q}$ non-co-deleted anaplastic glioma: a phase 3, randomised, open-label intergroup study. Lancet. 2017 Oct;390(10103):1645-53. https://doi.org/10.1016/S01406736(17)31442-3

22. Herrlinger U, Tzaridis T, Mack F, Steinbach JP, Schlegel U, Sabel M, et al. Lomustine-temozolomide combination therapy versus standard temozolomide therapy in patients with newly diagnosed glioblastoma with methylated MGMT promoter (CeTeG/ NOA-09): a randomised, open-label, phase 3 trial. Lancet. 2019 Feb;393(10172):678-88. https://doi.org/10.1016/S01406736(18)31791-4

23. Pace A, Dirven L, Koekkoek JAF, Golla H, Fleming J, Rudà $R$, et al. European Association for Neuro-Oncology (EANO) guidelines for palliative care in adults with glioma. Lancet Oncol. 2017 Jun;18(6):e330-e340. https://doi.org/10.1016/S14702045(17)30345-5

24. Pitter KL, Tamagno I, Alikhanyan K, Hosni-Ahmed A, Pattwell SS, Donnola S, et al. Corticosteroids compromise survival in glioblastoma. Brain. 2016 May;139(Pt 5):1458-71. https://doi. org/10.1093/brain/aww046

25. Statement from the Chief Investigators of the Randomised Evaluation of COVID-19 therapy (RECOVERY) Trial on dexamethasone. 2020.

26. Russell CD, Millar JE, Baillie JK. Clinical evidence does not support corticosteroid treatment for 2019-nCoV lung injury. Lancet. 2020 Feb;395(10223):473-5. https://doi.org/10.1016/S01406736(20)30317-2 